\title{
An Investigation into College Students' Motivation towards English Learning
}

\author{
Peiqiu Zhang \\ School of Foreign Languages \\ Zhejiang University of Science \& Technology \\ Hangzhou, China
}

\begin{abstract}
To investigate the self-determined motivation of non-English majors, 662 sophomores were measured using the adapted LLOS-IEA. The results prove the generalizability of a self-determination continuum in the Chinese context and indicate that compared with the students from the local college, students from the key university had a significantly higher degree of selfdetermination towards English study. Some pedagogical implications have been provided on how to improve students' self-determined motivation.
\end{abstract}

Keywords-self-determination theory; intrinsic motivation; extrinsic motivation; amotivation

\section{INTRODUCTION}

In the educational context, motivation has been widely accepted by both teachers and researchers as one of the key factors that influence the rate and success of L2 learning.

The present study was conducted to investigate college students' motivational orientations within the framework of self-determination theory[1]. This theory is closely linked to self-regulated learning and autonomy, both of which are important to the facilitation of better learning. Moreover, as self-determination theory views motivation as dynamic and adaptable through teacher intervention[2], it provides pedagogical solutions to the problem of how to increase students' internal motivation towards English learning.

\section{THEORETICAL FRAMEWORK}

SDT concerns human behavior from a new cognitive perspective and explains it in terms of the extent to which one fully accepts, endorses, or stands behind his actions. According to SDT, when a person's behavior is experienced as freely chosen and willingly enacted (self-determined) and when he acts in accord with his authentic interests or integrated values and desires, he will, therefore, be engaged in high degree of self-regulation, and on the contrary, if one's actions are experienced as controlled by forces that are phenomenally alien to the self or that if one is compelled to behave in specific ways regardless of one's values or interests, one is subjected to the external regulation. Based on the extent of self-determination involved in human activities, SDT distinguishes three general types of motivation, namely, intrinsic motivation, extrinsic motivation and amotivation.

Intrinsic motivation (IM), the most self-determined motivation, generally refers to motivation to willingly engage in a self-initiated activity because that activity is enjoyable and satisfying to do. Literature shows that intrinsic motivation has been associated with greater creativity, flexibility and spontaneity. As a further development of SDT, Vallerand and his colleagues divided IM into three subtypes. The first type of IM, IM-Knowledge, is the motivation for doing an activity for the feelings associated with exploring new ideas and developing knowledge. A second type, IM-Accomplishment, refers to the sensations related to attempting to master a task or achieve a goal. The third type, IM-Stimulation, relates to motivation based simply on the sensations stimulated by performing the task, such as aesthetic appreciation or fun and excitement.

Extrinsic motivation (EM) refers to the performance of an activity in order to attain some instrumental end, such as earning a reward or avoiding a punishment. It can be divided into three subtypes, each one increasingly self-determined. The extrinsically motivated behaviors that are least self-determined are referred to as external regulation, which involves the imposition by another person and is performed to satisfy an external demand. The second type of extrinsic motivation that is more internalized into the self-concept is interjected regulation, which refers to performing an activity due to some type of pressure that individuals have incorporated into the self, such that they compel themselves to carry out that activity. A more self-determined form of extrinsic motivation is regulation through identification. Identification reflects a conscious valuing of a behavioral goal or regulation, such that students would carry out the activity because of its importance for achieving a valued goal. A characteristic of the sub-types of EM is that they all imply some kind of external coercion which, once removed, may result in the language learner abandoning L2 learning

Amotivation (AM), the least self-determined end of the continuum, describes the state of lacking the intention to act. When amotivated, people either do not act at all or act without intent--they just go through the motions. Amotivation results from not valuing an activity, not feeling competent to do it, or not expecting it to yield the desired outcome

Different from Gardner's integrative-instrumental dichotomy, in the light of self-determination theory, extrinsic motivation is no longer regarded as an antagonistic counterpart of intrinsic motivation. Deci and Ryan maintained that different types of extrinsic motivation (EM) and intrinsic motivation (IM) could be classified along a continuum 
according to the extent to which they are internalized into the self-concept. Therefore, along the continuum, the concept of internalization describes how one's motivation for behavior can range from amotivation or unwillingness to passive compliance, to active personal commitment.

By offering a continuum of self-determination, SDT provides a comprehensive framework within which a large number of L2 learning motives can be organized systematically[3], in this way, it offers strong explanatory power for the various learning behaviors in those different persons with different degrees of willingness or selfdetermination may perform differently in their learning process. Secondly, by suggesting a dynamic process in which motivational orientations may change, it bears out the possibility that student's motivation in L2 learning may be enhanced provided with a supportive environment. Therefore, it provides great pedagogical significance in that various ways may be employed to facilitate such change, which may, in turn, contribute to students' language learning outcomes

\section{THE PRESENT STUDY}

The study is to examine: 1) The inter-correlations among the intrinsic motivation, extrinsic motivation and amotivation, and the potential existence of a self-determination continuum in the responses of these Chinese college students; 2) The difference between proficient and less proficient learners in motivational orientations. All the subjects were non-English majors and they came from different departments. According to their performance in the college entrance examination, subjects from Zhejiang University were taken as proficient language learners and those from Zhejiang University of Science \& Technology as less proficient ones. The data were collected through a 21-item questionnaire, adapted from Language Orientations Scale developed by Noels and collaborators. Combined with the quantitative investigation, a "richer" method of data collection--random interview was employed in the present study to allow for an explanation of participants' attitudes and opinions.

\section{RESUlTS AND DiSCUSSION}

\section{A. Existence of a self-determination continuum}

Following Noels, it was hypothesized that the strength of the correlations would increase the further one moved down the self-determination continuum from AM to EM to IM.

TABLE I. CORRELATIONS AMONG 7 MOTIVATIONAL SUBCATEGORIES

\begin{tabular}{|l|r|r|r|r|r|r|r|}
\hline & \multicolumn{1}{|c|}{ AMO } & \multicolumn{1}{c|}{ TER } & \multicolumn{1}{c|}{ TRO } & \multicolumn{1}{c|}{ DEN } & \multicolumn{1}{|c|}{ INK } & \multicolumn{1}{l|}{ INS } & INA \\
\hline AMO & 1 & & & & & & \\
\hline TER & -.02 & 1 & & & & & \\
\hline TRO & $-.17^{* *}$ & $.36^{* *}$ & 1 & & & & \\
\hline DEN & $-.48^{* *}$ & $.20^{* *}$ & $.37^{* *}$ & 1 & & & \\
\hline IM-K & $-.43^{* *}$ & -.04 & $.24^{* *}$ & $.54^{* *}$ & 1 & & \\
\hline IM-S & $-.37^{* *}$ & $.08^{*}$ & $.41^{* *}$ & $.54^{* *}$ & $.63^{* *}$ & 1 & \\
\hline IM-A & $-.37^{* *}$ & $.10^{* *}$ & $.42^{* *}$ & $.49^{* *}$ & $.57^{* *}$ & $.63^{* *}$ & 1 \\
\hline
\end{tabular}

Table I presents the inter-correlations among each motivation subscales. It shows that within the intrinsic motivation, IM-K, IM-S and IM-A are highly interrelated with each other $\left(.63^{* *}, .57^{* *}, .63^{* *}\right)$. In the category of extrinsic motivation, identified motivation, which is the most selfdetermined one in this part, shows the highest coefficient with intrinsic motivation $\left(.54^{* *}, .54^{* *}, .49^{* *}\right)$. Introjected motivation, which is second to the identified motivation, is not as positively related to intrinsic motivation as identified motivation does $\left(.24^{* *}, .41^{* *}, .42^{* *}\right)$. External motivation is much more positively related to Introjected (.36**) and Identified $\left(.20^{* *}\right)$ than intrinsic motivation (IM-K: no significant relation, IM-S: .086*, IM-K: .10**). All the EM and IM subscales negatively correlate with Amotivation as anticipated.

TABLE II. CORRELATIONS AMONG 3 BROAD MOTIVATIONAL ORIENTATIONS

\begin{tabular}{|l|r|r|r|}
\hline & \multicolumn{1}{|c|}{ AM } & EM & IM \\
\hline AM & 1 & & \\
\hline EM & $-.315\left(^{* *}\right)$ & 1 & \\
\hline IM & $-.461\left(^{* *}\right)$ & $.492\left(^{* *}\right)$ & 1 \\
\hline
\end{tabular}
** Correlation is significant at the 0.01 level (2-tailed).

Table II shows the relationship among 3 broad motivational orientations. Amotivation is negatively related to both extrinsic motivation (-.315**) and intrinsic motivation ($\left..461^{* *}\right)$, whereas the relationship between EM and IM is positive and strong $\left(.492^{* *}\right)$.

The correlation patterns in these two tables reveal strong evidence of a self-determination continuum from AM to IM and prove the generalizability of the self-determination theory to Chinese college students in that AM displays the least selfdetermination and it is followed by the three subcategories of EM in ordinal sequence, and the most self-determined goes to IM. In this regard, obviously, the self-determination framework may distinguish not only among the broad categories of AM, EM and IM but also reveal finer distinctions among the 3 subscales of EM, which constitute a continuum, from the most externally forced to the most selfdetermined.

\section{B. Comparison of motivational orientations between proficient learners and less proficient learners}

Table III shows the mean scores, standard deviations of each motivational subcategory on both proficient and less proficient learners, and T-Test results (Independent T-Test \& One-Sample T-Test)

TABLE III. THE MEAN SCORES, SD AND T-TEST RESULTS

\begin{tabular}{|c|c|c|c|c|c|c|c|}
\hline \multirow{2}{*}{} & \multicolumn{2}{|c|}{$\begin{array}{c}\text { Proficient } \\
\text { learners }\end{array}$} & \multicolumn{2}{c|}{$\begin{array}{c}\text { Less proficient } \\
\text { learners }\end{array}$} & \multirow{2}{*}{$\mathrm{t}$} & \multirow{2}{*}{ df } & $\begin{array}{c}\text { Sig.(2- } \\
\text { tailed) }\end{array}$ \\
\cline { 2 - 6 } & Mean & SD & Mean & SD & & & $.002^{* *}$ \\
\hline AM & 1.83 & .87 & 2.05 & 1.00 & -3.11 & 660 & .00 \\
\hline TER & $\mathbf{3 . 1 1}$ & .84 & $\mathbf{3 . 3 9 * *}$ & .93 & -4.11 & 660 & $.000^{* *}$ \\
\hline TRO & 2.49 & .86 & 2.45 & .92 & .515 & 660 & .607 \\
\hline DEN & $\mathbf{3 . 4 5}^{* *}$ & .90 & $\mathbf{3 . 1 2} *$ & .94 & 4.63 & 660 & $.000^{* *}$ \\
\hline IM-K & $\mathbf{3 . 1 5 * *}$ & 1.03 & 2.60 & 1.00 & 6.97 & 660 & $.000^{* *}$ \\
\hline IM-A & 2.87 & .96 & 2.69 & 1.01 & 2.38 & 660 & $.018^{*}$ \\
\hline IM-S & 2.60 & .91 & 2.40 & .89 & 2.92 & 660 & $.004^{* *}$ \\
\hline
\end{tabular}

$* *$ * the difference between the two groups is significant at the $0.01 / 0.05$ level (2-tailed). 
The above table reveals that for proficient learners, the mean scores in only three motivational orientations, namely, external motivation, identified motivation and IM-K are significantly higher than the hypothesized mean of 3 (representing a neutral score). In the case of less proficient learners, only on 2 subcategories, they got significantly higher scores than the neutral score 3 . The highest one goes to external motivation (3.39) and the second one is identified motivation (3.12). Moreover, the Independent-Samples T-Test results indicate that on the subcategories that lie on the more self-determined end of the continuum, namely, identified motivation, IM-K, IM-A and IM-S (identified motivation is regarded as the most self-determined extrinsic motivation), the proficient learners got significantly higher scores than the less proficient learners (Sig. $<0.05$ ). On the contrary, on the subtypes of "amotivation" and "external motivation", which lie on the less self-determined end of the continuum, the proficient learners got significantly lower mean scores than the less proficient learners as both of the Sig. values are lower than 0.01 .

Further analysis of their motivation components reveals that for both proficient and less proficient learners, the external motivation and identified motivation, which fall into the category of extrinsic motivation, rank top compared with the other motivational orientations. This suggests that on the one hand, the students value the importance of learning English well, on the other hand, there's no denying the fact that to some extent the need to learn English is externally imposed on the students and a majority of the students are actually forced to be involved in the English learning by the external demand and requirements. In the later interview, our assumption was confirmed. We were told that CET-4 \& CET6 are the most authoritative tests in the country which are closely related to their academic degree and future development, and are regarded as passports for getting a desirable job. For this reason, most students have the feeling that it is externally expected of them to learn English well.

However, different from the less proficient learners, proficient learners have obvious intrinsic motivation for knowledge (3.15) apart from extrinsic motivation. It is clear that one important reason for the proficient learners to pursue English study is to acquire more knowledge about English, about the English speaking community, their culture \& literature, etc, and they get pleasure from the English learning process. Combined with the previous findings, it can be concluded that for the proficient learners, despite the fact that they are somewhat externally controlled, they display a certain degree of self-determination in their English learning. As was indicated by Wen Qiufang, it is common for students to possess both intrinsic and extrinsic motivation, this result further proves the compatibility of these two kinds of motivations. Though both the proficient and less proficient learners have extrinsic motivation, the former display extrinsic motivation that entails personal endorsement and a feeling of free choice and self-determination, whereas the latter demonstrates compliance with external regulation. Therefore, they differ in their relative autonomy despite the instrumentalities they both have. From this, we can see that compared with Gardner's instrumental/integrative dichotomy
[4], the SDT framework really has a greater distinguishing power of motivation in terms of various levels of autonomy (self-determination) involved. Though the proficient learners are somewhat externally controlled, they have a relatively higher self-motivation, which predicts their more active commitment in self-regulatory study, while the less proficient learners conduct the learning activities with more or less a sense of coercion because their motive to learn English hasn't been internalized to be competently self-determined[5]. No wonder we found in the later interview of the less proficient students that a lot of them feel learning English tedious and painful, and more often than not, they suffer from different degrees of anxiety and frustration.

From what has been discussed above, we may reach the conclusion that although on the whole college students do not display satisfactorily high self-determination towards English learning and both proficient and less proficient learners have obvious extrinsic motivation, there does exist a significant difference between proficient and less proficient learners. Comparatively speaking, the proficient learners are more competently self-determined while the less proficient learners tend to be more externally oppressed.

\section{PEDAGOGICAL IMPLICATIONS}

Since self-determination theory views motivation, which is not only necessary, but prerequisite, as dynamic and adaptable that can be affected by the teacher, therefore no matter how proficient learners' English is, teachers should help students to enhance their self-determined motivation by internalizing the socially accepted learning goals and outcomes into what personally accepted as meaningful and relevant, that is, they should help students internalize the regulation of behaviors uninteresting yet valuable for effective functioning into something consistent with their own values. SDT assumes that when the value of an activity is internalized, people don't necessarily become more interested in the activities or more intrinsically motivated, but they do become more willing to do it because of its personal value. To facilitate this internalization process, students should be educated to see schooling and education as personally relevant to their interests and goals; besides, teachers' interventions should help to engage students in an inquiry about what they find meaningful. Teachers should also encourage students to explore goals that would be motivating to them. Classroom tasks and skill instruction should be planned around the accomplishment of these goals; even interventions that attempt to develop metacognitive and cognitive skills should be conducted in such a way as to be meaningful from the students' perceptive.

Teachers' belief in students is of vital importance. If they think some students are intrinsically motivated and selfdetermined, teachers will be more autonomy supportive with those students and will be more likely to believe those students have the ability to regulate themselves. On the other hand, if teachers think the students are extrinsically motivated and less self-determined, they will be more controlling with those students, believing they have to make the students perform the pre-designed tasks in educational settings. 
Therefore, teachers should believe in students' potential ability in self-regulation and should provide students with the opportunity to participate in the decision-making process for it will encourage self-determined regulation, which in turn is likely to produce beneficial learning outcomes. Meanwhile, teachers have to change their role from a dominant knowledge provider to a facilitator and a counselor, providing them with a moderate amount of freedom in choosing the content, methods, schedule, etc. Previous researches found that an autonomysupportive teacher is more likely to stimulate and retain students' natural curiosity (their intrinsic motivation for learning) and help them develop autonomous forms of selfregulation through the process of internalization [6]

\section{CONCLUSION}

Students' intrinsic motivation to engage in the learning process is not only necessary but a prerequisite. Teachers should take pedagogical interventions to help students, especially the less proficient students to internalize the learning behaviors so as to enhance their self-motivation, which will ultimately produce beneficial learning outcomes.

\section{REFERENCES}

[1] R. M. Ryan and E. L. Deci, "Intrinsic and extrinsic motivations: classic definitions and new directions”, Contemporary Educational Psychology, Vol. 25, pp. 54-67, January 2000.

[2] S.E. Deckner, "Quantitative evidence of the occurrence of a motivational dip in language learning in Year 7”, The Language Learning Journal, Vol. 47, pp. 625-641, October 2017.

[3] C.Z. Maria, and P.Matteo, "The effects of intrinsic and extrinsic motivation on students learning effectiveness. Exploring the moderating role of gender”, International Journal of Educational Management, Vol. 33, pp. 1381-1392, December 2019.

[4] Z. Dornyei, "Attitudes, orientations, and motivations in language learning: Advances in theory, research and applications”, Language Learning, Vol. 53, pp. 3-32, December 2010.

[5] T.B. Maureen, and M. Margaret, "Motivation, self-efficacy and learning strategies of university students participating in work-integrated learning”, Journal of Education and Work, Vol. 31, pp. 1-11, October 2018.

[6] R. M. Ryan and E. L. Deci, "Self-determination theory and the facilitation of intrinsic motivation, social development and well-being”, American Psychologist, Vol. 55, pp. 68-78, February 2000. 